\title{
АНАЛИЗ ПРИМЕНЕНИЯ ГАДЖЕТОВ СТУДЕНТАМИ В ОБРАЗОВАТЕЛЬНОМ ПРОЦЕССЕ
}

\author{
(С) Д.3. Газиева \\ ГГНТУ им. акад. М.Д. Миллионщикова, Грозный, Россия
}

В данной статье рассматриваются гаджеты, используемые студентами в процессе обучения, в большинстве случаев это ноутбуки, планшеты и смартфоны. Есть преподаватели, которые говорят, что использование гаджетов, как и любое другое социальное явление, имеет как положительные, так и отрицательные стороны:

- положительные моменты - это активное взаимодействие, наличие сенсорного экрана, занимающего мало места, возможность работы в группе, использование функции ноутбука или беспроводной сети, не связанной с конкретным местом, можно учиться, не выходя из дома, быстрый поиск необходимой информации;

- отрицательные стороны, маленький экран, ограничение памяти, необходимость подзарядки.

Ключевые слова: гаджет, смартфон, коммуникатор, планшет, ноутбук, социальные сети.

Образование - это процесс и результат осознания человеком знаний мира, ценностей, опыта, приобретенного предыдущими поколениями. Образование является одним из старейших и наиболее фундаментальных социальных институтов. На протяжении веков люди учились и развивались, создавая определенную систему знаний. Каждый из нас участвовал в образовательном процессе на протяжении всей своей жизни. Новые технологии не могли не оказать влияния на образование. Все больше «студентов» в мире не представляют свое обучение без современных гаджетов [4].

Гаджет с английского gadget - вещь, адаптация, установка, безделушка. Гаджет представляет собой небольшое 
устройство, предназначенное для облегчения и улучшения жизни человека. Цифровые фотоаппараты, коммуникаторы, планшеты, мобильные телефоны, GPS-навигаторы, MP3-плееры, USB являются нашими самыми распространенными гаджетами. [3].

В настоящее время преподаватели вузов обязаны создавать учебный контент на сайтах образовательных учреждений. В частности, в Грозненском государственном нефтяном техническом университете имени академика М. Д. Миллионщикова работает официальный сайт ГГНТУ на котором размещены темы для самостоятельных работ студентов. Также учебные программы по дисциплинам, для формирования конкретных компетенций у студентов. Преподавателями закладываются разные виды СРС, сделанные при помощи разнообразных средств информационно-коммуникационных технологий.

Стоит отметить, что, несмотря на активное использование гаджетов в учебном процессе, для одних студентов они являются хорошими помощниками и соответственно улучшают их результаты, а для других служат «медвежьей услугой» и негативно влияют на результаты обучения. Интересно понять, почему для одних использование гаджетов приводит к качественному скачку в эффективности тренинга, а для других это губительно и только мешает развитию программы [1].

Цель данного исследования - выявить и оценить роль, которую играют технические устройства в процессе обучения. Для того чтобы определить, как студенты относятся к гаджетам в образовательном процессе, мною был проведен опрос среди студентов 1-2 курсов разных факультетов, проживающих в общежитии ГГНТУ. Общее число респондентов составило 27 человек. Анкета состояла из 6 вопросов, касающихся личного отношения студентов к использованию гаджетов в учебном процессе. 
1. «Выберите техническое устройство, которое, по вашему мнению, наиболее эффективно для использования в учебном процессе».

Результаты показывают, что телефон является самым эффективным устройством для студентов, на втором месте - ноутбук, а затем планшет. Результаты были вполне предсказуемы, поскольку телефон сегодня является самым доступным, удобным, а также самым эффективным гаджетом для использования.

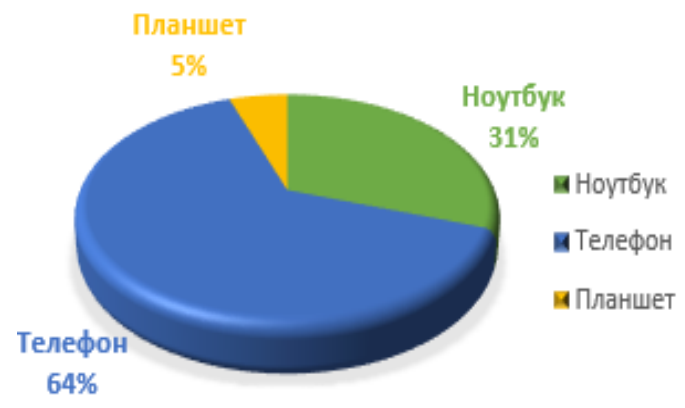

Рис. 1. Техническое устройство необходимое в учебном процессе

2. «Как вы думаете, можно ли пользоваться гаджетами во время уроков?»

Исходя из полученных результатов, был сделан вывод, что есть небольшое количество студентов, которые считают недопустимым использование гаджетов во время занятий. Но в то же время добрая половина опрошенных, наоборот, считает, что пользоваться телефоном на паре можно. Результат также очень ожидаем. Ведь на некоторых занятиях необходимо, например, обратиться к учебнику или учебному материалу. 


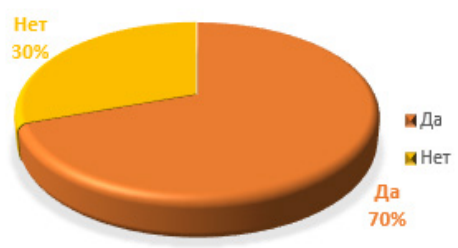

Рис. 2. Можно ли пользоваться гаджетами во время уроков

3. «Считаете ли вы, что гаджеты оказывают положительное влияние на обучение?»

Здесь большинство респондентов считают, что гаджеты оказывают положительное влияние на процесс обучения. Скорее всего, это связано с тем, что студенты активно используют смартфоны для чтения учебников во время лекций, для выполнения различных видов работ (самостоятельная работа студентов) в ноутбуке. Но некоторые из опрошенных считают, что гаджеты мешают учебному процессу. Студенты не всегда пользуются гаджетами во время занятий, а именно используют их не только для учебы, но и для личного пользования. И это отвлекает их от процесса обучения, что пагубно сказывается на восприятии информации. Они считают, что могут обойтись без гаджетов. В конце концов, наши предки прекрасно обходились без технологий.

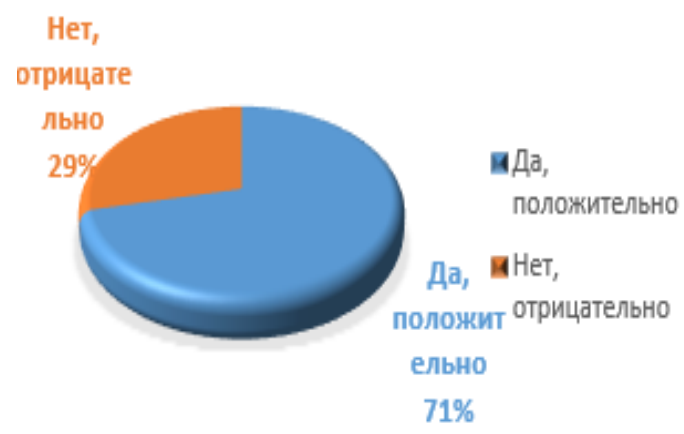

Рис. 3. Влияние на обучение 
4. «Как часто вы пользуетесь телефоном во время занятий?». Из результатов мы видим, что соотношение студентов, которые редко пользуются гаджетами, и тех, кто пользуется ими часто, составляет почти 50/50. Это связано с тем, что не все просматривают материал курса на смартфоне или каком-то другом устройстве. А используют гаджеты в качестве шпаргалок или для просмотра социальных сетей. А те студенты, которые часто используют гаджеты для просмотра материала дисциплины на гаджетах или для записи лекций.

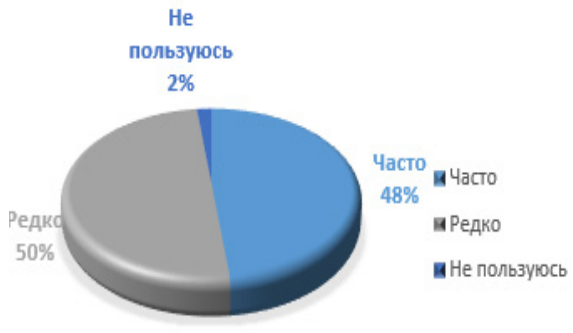

Рис. 4. Использование телефона во время занятий

4. «Для чего вы используете свой телефон во время занятий (если используете)?»

Большинство студентов используют гаджеты в качестве шпаргалок, что является большим недостатком. И только $37 \%$ студентов используют гаджеты во время лекций в учебных целях. Только 2\% не пользуются гаджетами

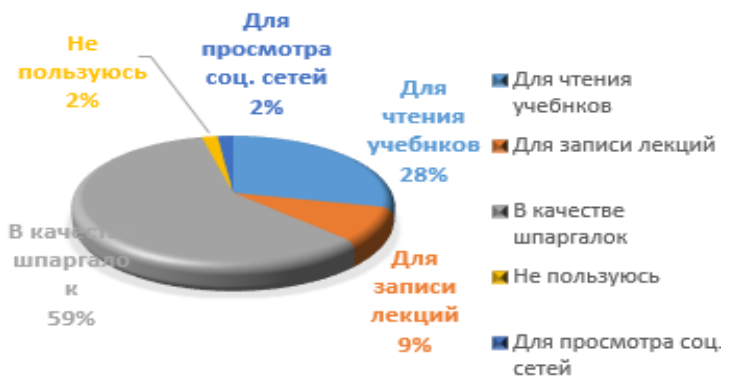

Рис. 5. Цели использования телефона во время занятий 
6. «Можно ли обойтись в учебе без технических устройств?»

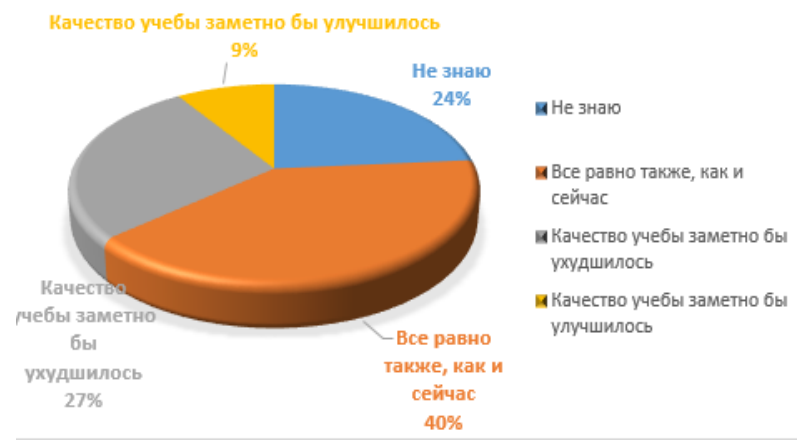

Рис. 6. Необходимость в учебе технических устройств

Здесь мы видим ответы студентов, в которых они оценивают, как бы они учились без технологических устройств. $40 \%$ респондентов считают, что отсутствие гаджетов не повлияет на их успеваемость. Это неплохой показатель того, что молодые люди не полностью доверяют техническим устройствам и предпочитают получать знания традиционным способом. 27\% респондентов из числа опрошенных считают, что без технических устройств они не справились бы с учебой.

Это показывает нам, что некоторые студенты уже полностью доверяют гаджетам и что в их отсутствие их успеваемость, конечно же, ухудшится. А тех, кто считает, что, наоборот, отсутствие гаджетов приведет к улучшению учебы, очень мало - 9\% опрошенных. Таким образом, с помощью технических устройств студенты получают долю информации, готовят домашние задания, пишут лекции, консультируются с учебниками по предмету - это положительные стороны их использования. Негативное влияние гаджетов на образовательный процесс учащихся включает в себя консультирование с ответами и решениями тестовых и само- 
образовательных заданий, консультирование в социальных сетях во время занятий [1].

Несмотря на все эти преимущества, гаджеты сильно мешают учебному процессу, в основном потому, что студенты используют их больше, как развлечение, чем как инструмент для получения знаний и опыта. Общение в различных социальных сетях, игры, во время лекций и практических занятий, что значительно снижает успеваемость студента.

Еще одним важным недостатком использования гаджетов в учебном процессе является возможность списывания с их помощью на различных тестах и экзаменах. Это не позволяет преподавателю оценить качество знаний студента, а также качество его собственной работы. Потому что преподавателю трудно определить, писал ли студент задание или списывал с помощью технологий. Это также влияет на уровень знаний самих студентов, ведь вместо того, чтобы готовиться к экзаменам, изучать материал, они занимаются простым переписыванием, а при таком подходе уровень знаний будущего специалиста будет недостаточным для выполнения работы, соответствующей полученной квалификации.

Современный человек вряд ли может представить свою жизнь без модных гаджетов. Люди по-разному относятся к новым изобретениям. Несмотря на все недостатки, преимуществ у гаджетов гораздо больше, ведь они позволяют экономить время и наслаждаться жизнью. Новые устройства облегчают нашу жизнь.

Очевидно, что данной теме плюсов больше, чем минусов, но ключ к использованию технологий в образовании всегда будет определяться отношениями между педагогом и учеником, потому что именно там происходит обучение. Технология может быть очень эффективным инструментом, но это всего лишь инструмент, и она не призвана заменить преподавателя, скорее идея заключается в том, чтобы создать комфортную учебную среду, которая позволит учеб- 
ному процессу перейти от организации к сотрудничеству и продуктивной учебной деятельности.

В данный момент можно сказать, что мы на первом этапе внедрения технологий в образование. Процесс внедрения может быть разочаровывающим, скучным, утомительным и длительным, но в конечном итоге технология может стать «окном» для нового эксперимента, открытий, способов обучения и сотрудничества учеников и педагогов [2].

. Из вышесказанного, а также по результатам проведенного опроса среди студентов следует вывод, что использование гаджетов в учебном процессе может быть полезным только в том случае, если студент достаточно самодисциплинирован.

\section{ЛИТЕРАТУРА}

1. Голицына И.Н., Половникова Н.Л. Мобильное обучение как новая технология в образовании // Образовательные технологии и общество. 2011. №1. С. 27-28.

2. Иванова, А. В. Влияние гаджетов на здоровье подростков / А. В. Иванова, Е. С. Гоголева. // Юный ученый. 2020. № 2.1 . С. 24-26

3. Соловьева Н.М., Макаренко Т.А. Применение ИКТ-технологий в организации педагогической практики студентов // Вестник Бурятского государственного университета. 2008. № 1. С. 117-121.

4. Протопопова С. В., Макаренко Т. А. Анализ применения гаджетов студентами в образовательном процессе // Научно-методический электронный журнал «Концепт». 2017. T. 32. C. 264-267. - URL: http://e-koncept.ru/2017/771077.htm.

5. Сайт журнала «Здоровье»: http://zdr.ru/articles/ elektronnue_deti Электронные дети2.http://shkolazhizni.ru/ archive/0/n-34786/ Гаджеты. Что это такое? 


\title{
ANALYSIS OF THE USE OF GADGETS BY STUDENTS IN THE EDUCATIONAL PROCESS OF
}

\author{
(C) D.Z. Gazieva \\ GSTOU named after M.D. Millionshchikov, Grozny, Russia
}

This article discusses gadgets used by students in the learning process, in most cases these are laptops, tablets and smartphones. There are teachers who say that the use of gadgets, like any other social phenomenon, has both positive and negative sides:

- the positive aspects are active interaction, the presence of a touch screen that takes up little space, the ability to work in a group, the use of a laptop function or a wireless network that is not connected to a specific place, you can study without leaving home, a quick search for the necessary information.

- negative sides, small screen, limited memory, the need to recharge.

Keywords: gadget, smartphone, communicator, tablet, laptop, social networks. 